\title{
Heterofucans from Dictyota menstrualis have anticoagulant activity
}

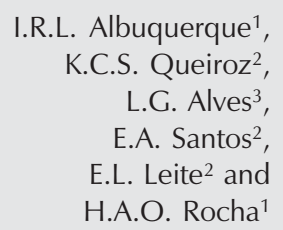

\author{
Laboratórios de ${ }^{1}$ Biotecnologia de Polímeros Naturais and \\ ${ }^{2}$ Glicobiologia, Departamento de Bioquímica, \\ Universidade Federal do Rio Grande do Norte, Natal, RN, Brasil \\ ${ }^{3}$ Disciplina de Biologia Molecular, Departamento de Bioquímica, \\ Universidade Federal de São Paulo, São Paulo, SP, Brasil
}

\begin{abstract}
Correspondence
H.A.O. Rocha

Departamento de Bioquímica

UFRN, Campus Universitário

59072-970 Natal, RN

Brasil

Fax: +55-84-211-9208.

E-mail: hugo-alexandre@uol.com.br

Presented at the XVIII Annual Meeting of the Federação de Sociedades de Biologia Experimental, Curitiba, PR, Brazil, August 27-30, 2003.

Research supported by CAPES and CNPq.

Publication supported by FAPESP.
\end{abstract}

Received April 25, 2003 Accepted October 24, 2003

\begin{abstract}
Fucan is a term used to denote a family of sulfated L-fucose-rich polysaccharides which are present in the extracellular matrix of brown seaweed and in the egg jelly coat of sea urchins. Plant fucans have several biological activities, including anticoagulant and antithrombotic, related to the structural and chemical composition of polysaccharides. We have extracted sulfated polysaccharides from the brown seaweed Dictyota menstrualis by proteolytic digestion, followed by separation into 5 fractions by sequential acetone precipitation. Gel electrophoresis using $0.05 \mathrm{M}$ 1,3-diaminopropane-acetate buffer, $\mathrm{pH}$ 9.0 , stained with $0.1 \%$ toluidine blue, showed the presence of sulfated polysaccharides in all fractions. The chemical analyses demonstrated that all fractions are composed mainly of fucose, xylose, galactose, uronic acid, and sulfate. The anticoagulant activity of these heterofucans was determined by activated partial thromboplastin time (APTT) using citrate normal human plasma. Only the fucans F1.0v and F1.5v showed anticoagulant activity. To prolong the coagulation time to double the baseline value in the APTT, the required concentration of fucan F1.0v $(20 \mu \mathrm{g} / \mathrm{ml})$ was only 4.88 -fold higher than that of the low molecular weight heparin Clexane ${ }^{\circledR}(4.1 \mu \mathrm{g} / \mathrm{ml})$, whereas $80 \mu \mathrm{g} / \mathrm{ml}$ fucan 1.5 was needed to obtain the same effect. For both fucans this effect was abolished by desulfation. These polymers are composed of fucose, xylose, uronic acid, galactose, and sulfate at molar ratios of 1.0:0.8:0.7:0.8:0.4 and 1.0:0.3:0.4:1.5:1.3, respectively. This is the fist report indicating the presence of a heterofucan with higher anticoagulant activity from brown seaweed.
\end{abstract}

Key words

- Fucan

- Fucoidan

- Anticoagulant drugs

- Brown algae

- Antithrombotic agents

........................
The leading causes of death in the United States are diseases of the heart and blood vessels, with the consequent occurrence of thrombosis. The death rate due to thrombosis is almost twice the rate due to cancer, which is the second cause of death in the US (1).
An ideal anticoagulant should have the following features: effectiveness, safety and lack of serious toxicity, a mechanism of action independent of the metabolic pathway of vitamin $\mathrm{K}$ (metabolism independent of the cytochrome p-450 system), a wide therapeutic window, no need for monitoring, oral 
bioavailability (for long-term use), safety during pregnancy, low cost, and a short halflife for drugs used in the acute setting of thrombosis or a long half-life for prophylaxis (2). However, the drugs currently used as anticoagulants have various limitations, thus being far from ideal. This explains current efforts to develop specific and potent anticoagulant agents. Several compounds have been shown to be effective in ex vivo or animal thrombosis models. Among them, sulfated polysaccharides are the compounds most extensively studied.

Unfractionated heparins and low molecular weight heparins (LMWH) are the only sulfated polysaccharides currently used as anticoagulants. However, heparins have several limitations such as dependence on antithrombin for their anticoagulant action, the need to monitor their effect, lack of general availability of anti-factor Xa assays, inability to bind to and inactivate cell membraneand clot-bound thrombin and platelet-bound factor Xa, potential development of heparininduced thrombocytopenia, osteoporotic effect of long-term use, dose-dependent clearance and lack of a linear dose-response curve, and lack of oral bioavailability. LMWH have significantly improved heparin management since monitoring is not needed in most patients and the dose response is predictable. They also cause less osteoporosis than unfractionated heparins and involve a reduced risk of inducing heparin-induced thrombocytopenia. However, several of the above limitations of heparin continue to limit its usefulness. However, in the last decade there was a tremendous increase in the sales of LMWH, reaching 2.5 billion dollars in 1999 compared to 150 million dollars for unfractionated heparins (1).

The various limitations of heparin and LMWH have led to the development of other sulfated polysaccharides that are more effective, safer, and easier to use anticoagulants for the short-term treatment of arterial and venous thromboembolic disorders and for the long-term prevention of recurrences. These agents are fucan, pentosan sulfate (3), galactan, fucosylated chondroitin (4), heparan sulfate from different sources, and other sulfated glycosaminoglycans from invertebrates (1). Among them, fucans are the sulfated polysaccharides from vegetal source most extensively studied as anticoagulant compounds (5).

Fucan is a term used to denote a family of sulfated L-fucose-rich polysaccharides with extremely variable molecular weights. They are extracted mainly from the extracellular matrix of brown seaweed (6) and from the egg jelly coat of sea urchin (7).

Since the first description of the fucans isolated from algae, these polysaccharides have been widely tested for biological activities in different mammalian systems. Plant fucans have antiviral (8), anti-adhesion (9), anticoagulant (10), and anti-inflammatory activity, as well as antiproliferative and antitumoral properties (5). The structures of these fucans vary among species and sometimes among different parts of seaweed (11). Furthermore, in contrast to animal fucans, algal fucans contain portions of other neutral sugars and uronic acids in addition to sulfate and fucose. Therefore, each new fucan purified is a new compound with unique structural features, thus representing a potential novel drug.

The structural characteristics of fucans necessary for all of the biological activities cited above have not been determined; consequently, the relationships between structure and biological activities have not been clearly established. Most of the difficulties for these studies arise from the fact that these compounds are highly heterogeneous with complex NMR spectra with broad signals that hamper resolution (12). In fact, even high-field NMR is of limited value for these plant polysaccharides, and complete descriptions of their structures are not available at present. However, meaningful structural studies with NMR are possible with relatively 
low molecular weight fucans (LMWFs) prepared by several methods such as acid hydrolysis of high molecular weight fucans (10) or extracted from brown seaweed (13). The extraction of LMWFs from brown seaweed would be very important to determine the structure/biological activity relationships of fucans.

We extracted LMWFs from the brown seaweed Dictyota menstrualis. Briefly, the alga was dried and $50 \mathrm{~g}$ of dried powder was suspended with 5 volumes of $0.25 \mathrm{M} \mathrm{NaCl}$ and the $\mathrm{pH}$ of the mixture was adjusted to 8.0 with $\mathrm{NaOH}$. Ten milligrams of maxatase, an alkaline protease from Esporobacillus (BioBras, MG, Brasil), was then added to the mixture for proteolytic digestion. After a 24-h incubation at $60^{\circ} \mathrm{C}$ with agitation the mixture was filtered through cheesecloth. The fractionation of the filtrate by precipitation with acetone was as follows: a 0.5 volume of ice-cold acetone was added to the solution which was kept at $4^{\circ} \mathrm{C}$, under gentle shaking, and the solution was left to stand at the same temperature for an additional $24 \mathrm{~h}$. The precipitate formed was collected by centrifugation at $10,000 \mathrm{~g}$ for $20 \mathrm{~min}$, dried under vacuum, resuspended in distilled water, and analyzed. Acetone, 1.0, 1.5, 2.0, and 3.0 volumes calculated from the initial solution, was added to the supernatant and the operations were repeated as described above. With this procedure, we obtained five fractions named fractions F0.5v, F1.0v, F1.5v, F2.0v and F3.0, respectively. For fucan visualization, the fractions were submitted to agarose gel electrophoresis in $0.05 \mathrm{M} 1,3-$ diaminopropane-acetate buffer, $\mathrm{pH} 9.0$ (11) and the gel was dried and stained for $15 \mathrm{~min}$ with $0.1 \%$ toluidine blue in acetic acid/ethanol/water $(0.1: 5: 4.9, \mathrm{v} / \mathrm{v})$. The gel was then destained with the same solvent.

The electrophoretic profiles showed the presence of a polydisperse component in fraction F1.0v, while the other fractions showed a single band each (Figure 1). Table 1 shows the molecular weight of the fraction components, determined by HPLC in $0.2 \mathrm{M}$ $\mathrm{NaCl}, 0.5 \%$ ethanol, using a GF-250 column (Asahipak GF series, Asahi Chemical Industry Co., Yakoo, Japan). The column was calibrated with standard glycosaminoglycans.

The sugar composition of the polymers was determined by paper chromatography and by gas-liquid chromatography of alditol acetate as derivative (13). The polymers are composed mainly of fucose, galactose, xylose, and uronic acid (Table 1) and are composed of heterofucans with a significant proportion of non-fucose sugar components. These heterofucans have been described since 1950 (6) and in some cases galactose was reported to be a major component $(14,15)$. Because they have not been frequently described, we decided to analyze the anticoagulant activity of these LMWFs from D. menstrualis.

Several homofucans showing anticoagu-

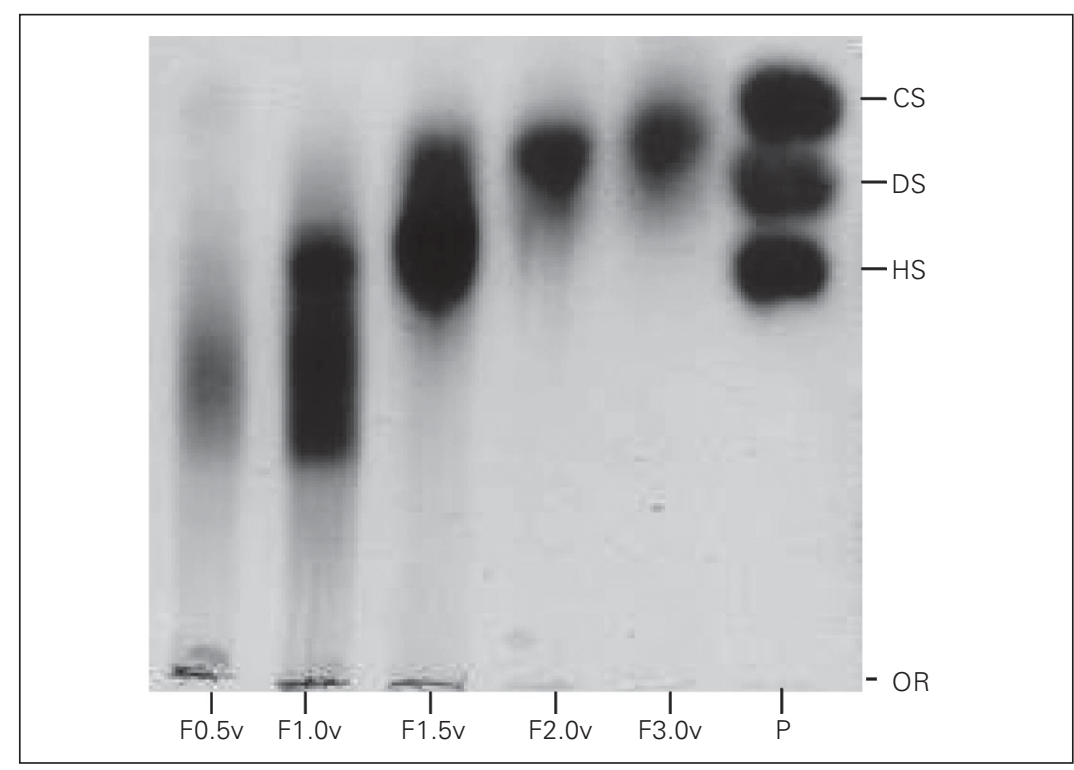

Figure 1. Diaminopropane acetate electrophoresis of the heterofucan fractions. Fivemilliliter aliquots of the fractions shown were applied to agarose gel $(7.5 \times 10 \mathrm{~cm}, 0.2-\mathrm{cm}$ thick) prepared in $0.05 \mathrm{M}$ 1,3-diaminopropane-acetate buffer, $\mathrm{pH}$ 9.0, and subjected to electrophoresis at $110 \mathrm{~V} / \mathrm{cm}$ for $60 \mathrm{~min}$. The gels were then maintained in $0.1 \%$ cetyltrimethylammonium bromide for $4 \mathrm{~h}$ and dried, and the polysaccharides were stained with $0.1 \%$ toluidine blue in a solution containing $50 \%$ ethanol and $1 \%$ acid acetic in water for 15 $\mathrm{min}$. The gels were then destained with the same solution without toluidine blue. P, $10 \mu \mathrm{g}$ each of heparan sulfate (HS), dermatan sulfate (DS), and chondroitin sulfate (CS). F0.5v, F1.0v, F1.5v, F2.0v, F3.0v = fucans precipitated with $0.5,1.0,1.5,2.0$ and 3.0 acetone volumes. $\mathrm{OR}=$ origin. 
lant activity have been extracted from different brown seaweeds (3). However, there are only few reports on the anticoagulation mechanism of homofucans. In general, the proposed mechanism of action is a predominantly direct one on antithrombin (thrombin-fibrinogen complex) and on heparin cofactor II-mediated antithrombin activities, with a minor involvement of antithrombin III. Their anticoagulant activities depend on their sulfate content and molecular weight $(10,11,16,17)$. On the other hand, to the best of our knowledge, there are no data about the mechanism of action of heterofucans.

In our case, only fractions F1.0v and F1.5v obtained from D. menstrualis showed anticoagulant activity (Table 1). Interestingly, $\mathrm{F} 1.0 \mathrm{v}$ was a more potent anticoagulant than $\mathrm{F} 1.5 \mathrm{v}$ in spite of being less sulfated. There-

\begin{tabular}{|c|c|c|c|c|c|c|c|}
\hline Fucans & APTT & MW & Fucose & Xylose & Uronic acid & Galactose & $\mathrm{SO}_{3} \mathrm{Na}$ \\
\hline F0.5v & nd & 9,000 & 1 & 0.4 & 0.8 & 0.8 & 0.04 \\
\hline F1.0v & 20 & 9,300 & 1 & 0.8 & 0.7 & 0.8 & 0.4 \\
\hline F1.5v & 80 & 9,100 & 1 & 0.3 & 0.4 & 1.5 & 1.3 \\
\hline $\mathrm{F} 2.0 \mathrm{v}$ & nd & 9,200 & 1 & 0.7 & 0.2 & 1.2 & 1.1 \\
\hline F3.0v & nd & 8,900 & 1 & 1.1 & 0.5 & 1.0 & 1.2 \\
\hline DF1.0v & nd & 8,750 & 1 & 0.7 & 0.7 & 0.7 & 0.02 \\
\hline DF1.5v & nd & 7,200 & 1 & 0.3 & 0.4 & 1.3 & 0.3 \\
\hline Heparin & 0.6 & 12,000 & - & - & - & - & - \\
\hline Clexane ${ }^{\circledR}$ & 4.1 & 4,500 & - & - & - & - & - \\
\hline
\end{tabular}

Data are reported as concentration $(\mu \mathrm{g} / \mathrm{ml})$ required to double APTT compared to minus fucan control. The standard deviation was $8-12 \%$ for three measurements. Molecular weight (MW) was determined by HPLC using glycosaminoglycans as standard. APTT $=$ activated partial thromboplastin time; $\mathrm{nd}=$ anticoagulant activity not detected with up to $200 \mu \mathrm{g} / \mathrm{ml}$; DF1.0v = desulfated F1.0v, and DF1.5v = desulfated F1.5v. Value determined for the control $=36.4 \mathrm{~s}$. fore, the increased anticoagulant activity of $\mathrm{F} 1.0 \mathrm{v}$ is unlike to be merely a charge density effect. These fucans were desulfated by solvolysis in dimethylsulfoxide as previously described (6) and both heterofucans lost their anticoagulant activity after desulfation (Table 1).

The anticoagulant activity was determined by activated partial thromboplastin time (APTT). This assay was carried out according to the manufacturer specification (Labtest, São Paulo, SP, Brazil) as previously described (4). Briefly, citrate normal human plasma $(90 \mu \mathrm{l})$ was mixed with $10 \mu \mathrm{l}$ solution of F1.0v or F1.5v at different concentrations and incubated for $1 \mathrm{~min}$ at $37^{\circ} \mathrm{C}$. Then, APTT assay reagent $(100 \mu \mathrm{l})$ was added to the mixture and incubated for $6 \mathrm{~min}$ at $37^{\circ} \mathrm{C}$. Thereafter, $20 \mathrm{mM} \mathrm{CaCl}_{2}(100 \mu \mathrm{l})$ was added and the clotting time was recorded. The time of control (without fucans) was $36.4 \mathrm{~s}$. To prolong the coagulation time to double the baseline value in the APTT, the required concentration of LMWF F1.0v $(20 \mu \mathrm{g} / \mathrm{ml})$ was 4.88-fold higher than that of the LMWH Clexane $^{\circledR}(4.1 \mu \mathrm{g} / \mathrm{ml})$. This was an interesting result, since Millet et al. (18) have shown that a higher concentration $(>50 \mu \mathrm{g} / \mathrm{ml})$ of an LMW homofucan was required for an equivalent prolongation of the APTT.

Heterofucans with similar chemical composition of $\mathrm{F} 1.0 \mathrm{v}$ and $\mathrm{F} 1.5 \mathrm{v}$ isolated from brown algae Spatoglossum schröederi (13) and Sargassum stenophyllum (15), have shown very low anticoagulant activity, suggesting that the anticoagulant heterofucans from $D$. menstrualis have distinct structural features.

\section{References}

1. Nader HB, Pinhal MAS, Baú EC et al. (2001). Development of new heparin-like compounds and other antithrombotic drugs and their interaction with vascular endothelial cells. Brazilian Journal of Medical and Biological Research, 34: 699-709.

2. Moll S \& Roberts HR (2002). Overview of anticoagulant drugs for the future. Seminars in Hematology, 39: 145-157.

3. Nishino T, Fukuda A, Nagumo T, Fujihara M \& Kaji E (1999). Inhibi- tion of the generation of thrombin and factor Xa by a fucoidan from the brown seaweed Ecklonia kurome. Thrombosis Research, 96: 37-49.

4. Pereira MS, Vilela-Silva AC, Valente AP \& Mourão PA (2002). A 2sulfated, 3-linked alpha-L-galactan is an anticoagulant polysaccharide. Carbohydrate Research, 337: 2231-2238.

5. Boisson-Vidal C, Haroun-Bouhedja F, Ellouali M, Blondin C, Fischer 
AM, Agostini A \& Jozefonvicz J (1995). Biological activities of polysaccharides from marine algae. Drugs of the Future, 20: 1237-1249.

6. Kloareg B \& Quatrano RS (1988). Cell walls of marine algae: structure and function. Oceanography and Marine Biology, an Annual Review, 26: 259-315.

7. Vilela-Silva $\mathrm{AC}$, Castro MO, Valente AP, Biermann $\mathrm{CH}$ \& Mourão PAS (2002). Sulfated fucans from the egg jellies of the closely related sea urchins Strongylocentrotus droebachiensis and Strongylocentrotus pallidus ensure species-specific fertilization. Journal of Biological Chemistry, 277: 379-387.

8. Ponce NM, Pujol CA, Damonte EB, Flores ML \& Stortz CA (2003). Fucoidans from the brown seaweed Adenocystis utricularis: extraction methods, antiviral activity and structural studies. Carbohydrate Research, 338: 153-165.

9. Rocha HAO, Franco CRC, Trindade ES, Carvalho LCM, Veiga SS, Leite EL, Dietrich CP \& Nader HB (2001). A fucan from the brown seaweed Spatoglossum schröederi inhibits Chinese hamster ovary cell adhesion to several extracellular matrix proteins. Brazilian Journal of Medical and Biological Research, 34: 621-626.

10. Haroun-Bouhedja F, Mostafa E, Sinquin C \& Boisson-Vidal C (2000). Relation between sulfate groups and biological activities of fucans. Thrombosis Research, 100: 453-459.

11. Dietrich CP, Farias GGM, Abreu LRD, Leite EL, Silva LF \& Nader HB (1995). A new approach for characterization of polysaccharides from algae: Presence of four main acidic polysaccharides in three species of the class Phaeophycea. Plant Science, 108: 143-153.
12. Chevolot L, Foucault A, Chaubet F, Kervarec N, Sinquin C, Fisher A \& Boisson-Vidal C (1999). Further data on the structure of brown seaweed fucans: relationships with anticoagulant activity. Carbohydrate Research, 319: 154-165.

13. Leite EL, Medeiros MGL, Rocha HAO, Farias GGM, Silva LF, Chavante SF, Abreu LRD, Dietrich CP \& Nader HB (1998). Structure and pharmacological activities of sulfated xylofucoglucuronan from the alga Spatoglossum schröederi. Plant Science, 132: 215-228.

14. Hussein MMD, Abdel-Aziz A \& Salem HMI (1980). Some structural features of a new sulphated heteropolysaccharides from Padina povonia. Phytochemistry, 19: 2133-2135.

15. Duarte MER, Cardoso MA, Noseda MD \& Cerezo AS (2001). Structural studies on fucoidan from brown seaweed Sargassum stenophyllum. Carbohydrate Research, 333: 281-293.

16. Nishino $T$, Aizu $Y$ \& Naguno $T$ (1991). The influence of sulfate content and molecular weight of a fucan sulfate from brown seaweed Ecklonia kurome on its antithrombim activity. Thrombosis Research, 64: 723-731.

17. Pereira MS, Mulloy B \& Mourão PAS (1999). Structure and anticoagulant activity of sulfated fucans. Journal of Biological Chemistry, 274: 7656-7667.

18. Millet J, Jouault SC, Mauray S, Theveniaux J \& Sternbrg C (1999). Antithrombotic and anticoagulant activities of a low molecular weight fucoidan by the subcutaneous route. Trombosis and Haemostasis, 81: 391-395. 